\title{
Surface Enrichment of Low Gold Alloys
}

\section{Gunnar Hultquist}

Department of Physical Chemistry, The Royal Institute of Technology, Stockholm, Sweden

Characteristic dissolution kinetics, obtained from a nuclear tracer technique (gammaspectrometry) and surface analysis (ESCA) measurements, of some metals and alloys immersed in chloride-containing water arepresented. The tarnishing of low gold alloys in simulated saliva solutions is shown to be less severe when silver is exchuded as an alloying element in these alloys. Experimental data on interdiffusion at room temperature of a goldcopper-zinc alloy are presented, and it is seen that these diffusion data predict the lowest possible dissolution rate of the alloy exposed to an aqueous solution.

Many commercial alloys are characterized by a compromise in economy and performance, in which the compositions of the alloys are a function of relative costs and properties of the component elements. Stainless steel is a well known example in which the chromium protects the alloy from corrosion while the presence of iron gives the alloy suitable mechanical properties. However, in certain environments alloys might fail in performance. Many ironchromium alloys suffer from localized corrosion in chloridecontaining media like sea water (1). Gold alloys have many applications in dentistry, jewellery and industrial areas. For economic reasons much effort has been made in the last 5 years or so to lower the gold content of such alloys whilst retaining the unique properties of them. However a number of low-gold alloys have been shown to be sensitive to tarnishing with accompanying formation of corrosion products (2). In particular when these alloys contain substantial amounts of silver, a reduction in brightness is often observed in sulphide-containing solutions such as saliva. In a recently published work $(3)$ the tarnishing oflow gold alloys $(\sim 30$ atomic per cent gold) with different proportions of silver, copper and zinc was investigated in some detail. The phenomenon of selective dissolution of copper and zinc from the alloys turned out to be the main criterion for the occurrence or absence of tarnish in these alloys. This communication describes the selective dissolution from primarily low gold alloys as it occurs during normal immersion in near neutral $(\mathrm{pH}=5.7)$ solutions in air contact.

\section{Dissolution from Some Metals and Alloys}

The preparation of test materials and solutions, and experimental procedures have been detailed elsewhere (3), and in

Table I

Test Alloy Designations and Compositions

\begin{tabular}{c|c|c} 
Alloy & Weight \% & Atomic \% \\
\hline A1 & $\mathrm{Au}_{55} \mathrm{Cu}_{35} \mathrm{Zn}_{10}$ & $\mathrm{Au}_{28} \mathrm{Cu}_{55} \mathrm{Zn}_{17}$ \\
A2 & $\mathrm{Fe}_{80} \mathrm{Cr}_{18} \mathrm{Mo}_{2}$ & $\mathrm{Fe}_{80} \mathrm{Cr}_{18} \mathrm{Mo}_{2}$ \\
A3 & $\mathrm{Co}_{{ }_{65}} \mathrm{Cr}_{30} \mathrm{Mo}_{5}$ & $\mathrm{Co}_{65} \mathrm{Cr}_{32} \mathrm{MoO}_{3}$ \\
A4 & $\mathrm{Au}_{55} \mathrm{Cu}_{45}$ & $\mathrm{Au}_{28} \mathrm{Cu}_{72}$ \\
A5 & $\mathrm{Au}_{44} \mathrm{Ag}_{58}$ & $\mathrm{Au}_{30} \mathrm{Ag}_{70}$
\end{tabular}

this short article we will restrict ourselves to reporting on and discussing the immersion and surface enrichment experiments, and examination of the alloy surfaces. The compositions of the various alloys which were prepared as single phase samples are given in Table I. From gammaspectrometry measurements, amounts of gold, copper and zinc found in the solution $(0.025 \mathrm{M} \mathrm{NaCl})$ after various

Fig. 1 Accumulative release of copper, zinc and gold from alloy Al after different times of exposure in water containing $\sim 1 \%$ chlocide. Gammaspectrometry examination

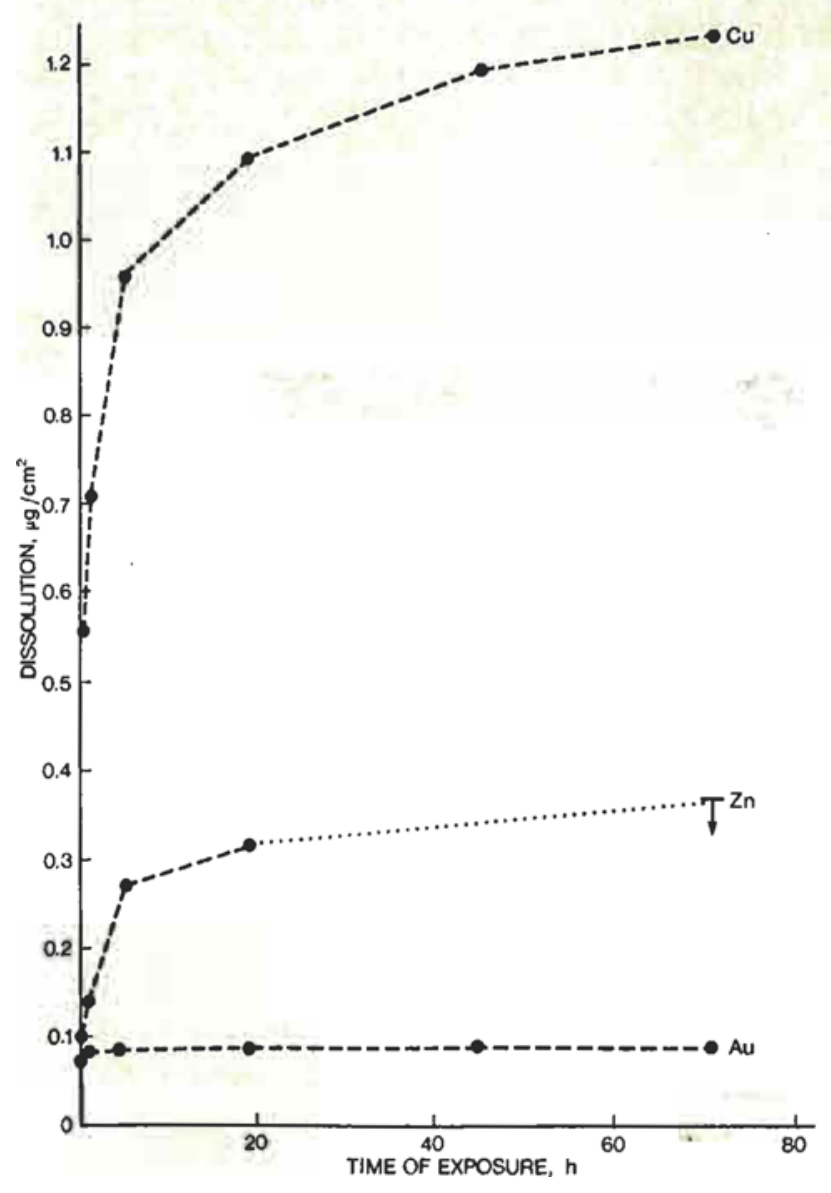




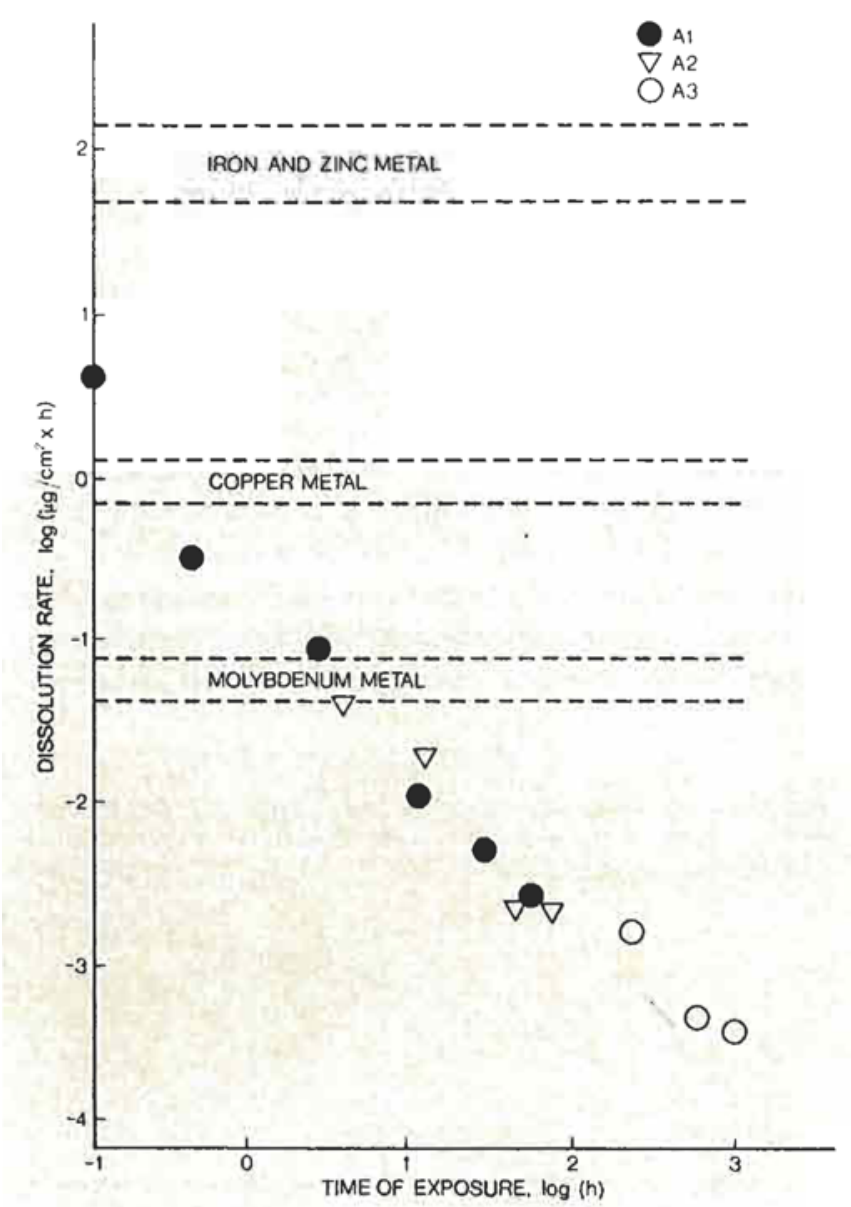

times of immersion of alloy A1 are shown in Figure 1 (experimental details of the gammaspectrometry technique are given in (4)). After each analysis of the $300 \mathrm{ml}$ solution volume (in which a $10 \mathrm{~cm}^{2}$ area of alloy surface was exposed) it was renewed to ensure identical solution chemistry at the beginning of each period of exposure. Obviously, from Figure 1, a pronounced preferential dissolution of copper and zinc relative to gold takes place. The monotonous decrease in overall dissolurion rate is expressed in Figure 2 . Similar dissolution kinetics have been found from two other alloys, A2 and A3 (see Table I) as shown in the same figure. Cobalt (5) and iron (6) respectively, are preferentially removed in alloys $A 3$ and $A 2$ in an analogous manner to zinc and copper in the gold-copper-zincalloy. As pure metals, zinc, iron, copper and molybdenum dissolve at constant rates under these conditions of immersion (Figure 2). This should also be the case for cobalt, although experimental data are lacking.

The enrichment of certain alloy components, gold in the goldcopper-zinc alloy and chromium (oxide) in the chromium-

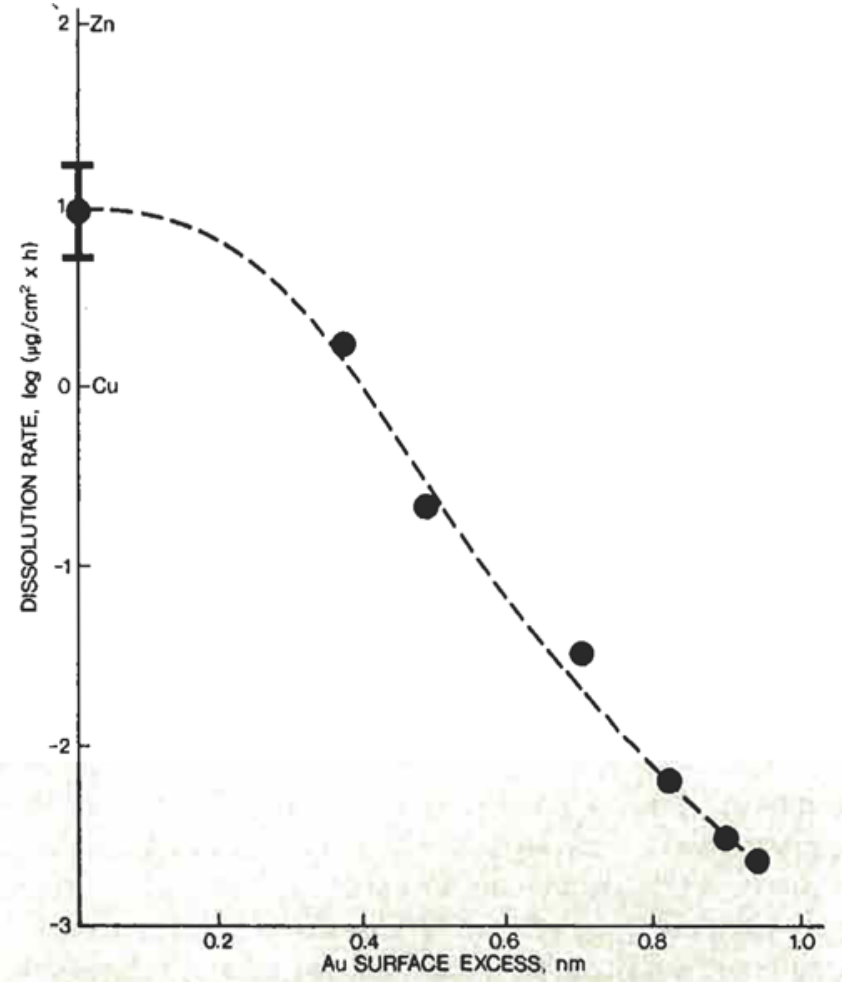

Fig. 2 (left) Total dissolution rates from alloys $\mathrm{A1}, \mathrm{A} 2$ and $\mathrm{A} 3$ as well as dissolution rates from iron, zinc, copper and molybdenum as pure metals in water containing $\sim 1 \%$ chloride. Gammaspectrometry examination

Fig. 3 (above) Total dissolution rates from alloy A1 vs. gold surface enrichment expressed as a thickness of a pure gold overlayer with the density of gold $\left(19.3 \mathrm{~g} / \mathrm{cm}^{3}\right)$. Dissolution rates of copper and zinc are indicated. Data from Figs. 1 and 2. Gammaspectrometry examination

containing alloys (A2, A3), is a natural consequence of the selective removal of the less stable alloy components. The following presentation of experimental data attempts to throw some light on the surface enrichment of gold alloys and its consequences.

\section{Surface Excess of Gold \\ Gamma Spectrometry Examination}

The enrichment of a surface with gold relative to nominal alloy content, is a consequence of the preferential removal of copper and zinc. This gold excess amounts to:

$$
\triangle \mathrm{m}(\mathrm{Au})=\frac{54.5}{45.5} \cdot \mathrm{m}(\mathrm{Cu}+\mathrm{Zn})-\mathrm{m}(\mathrm{Au})
$$

where $\triangle \mathrm{m}(\mathrm{Au})$ is the excess of gold in $\mu \mathrm{g} / \mathrm{cm}^{2}$, the numbers 54.5 and 45.5 are the gold and copper + zine weight per cent alloy contents respectively (Alloy 1 ).

Assuming the excess of gold to be existing in a thin overlayer and having a density of gold $\left(19.3 \mathrm{~g} / \mathrm{cm}^{3}\right)$ then the thickness of such a pure gold overlayer simply is: 


$$
\mathrm{d}(\mathrm{Au})=\Delta \mathrm{m}(\mathrm{Au}) / 1.93 \mathrm{~nm}
$$

These calculations have been made on the dissolution data in Figure 1 and the dissolution rate $v s, \mathrm{~d}(\mathrm{Au})$ is seen in Figure 3. Obviously, a very thin $(<1 \mathrm{~nm})$ gold overlayer, a small amount of gold surface excess, suppresses considerably the total dissolution. The initial dissolution rate of the alloy, at gold overlayer thickness $\mathrm{d}(\mathrm{Au})=0$, is in magnitude the sum of the individual dissolution rates of the pure elements copper and zinc.

\section{Examination by ESCA}

The surface sensitivity in the ESCA technique (Electron Spectroscopy for Chemical Analysis) is in the nanometer range. An exponential intensity decay $v$ s. depth of the detected photoelectrons applies in this technique (7). Having a gold overlayer on a gold alloy substrate the integrated gold content (atomic per cent gold) ESCA $_{\text {in }}$ being measured equals:

$(\text { at. } \% A u)_{\text {ESCA }}=(\text { at. } \% A u)_{\substack{\text { OYER } \\ \text { L }}}\left(1-\mathrm{e}^{\frac{-D}{\lambda}}\right)+(\text { at.\% Au })_{\text {SUBSTR } M T E} \cdot e^{\frac{-D}{\lambda}} 3$

This equation has been used when evaluating the surface compositions of gold alloys after different periods of immersion in various solutions (3). Primarily, what we achieve are the

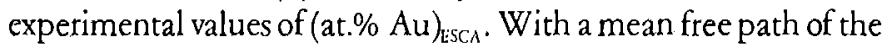
detected photoelectrons of $1.5 \mathrm{~nm}=\lambda$ and a nominal gold content in the alloy of 28 atomic per cent, equation 3 can easily be used to calculate the thicknesses, D, of pure gold overlayers (at.\%

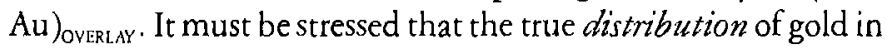
the surface might deviate from the model of a simple pure overlayer of gold. On the other hand, after immersions of alloy A1 (A2) it was found that the surface enrichment with gold (chromium) occurs within a $\sim 1 \mathrm{~nm}$ thick surface layer with (probably) pure gold (chromium (oxide)) constituting the outermost surface $(3,6)$.

Alloy $A 1$ has been immersed in pure water and $0.025 \mathrm{M} \mathrm{NaCl}$ respectively. The enrichment by gold, calculated as above, after different times of exposure is presented in Figure 4 . The addition of the salt accelerates the selective dissolution of copper and zinc as interpreted from this figure. Dissolution of copper from copper metal has also been found to increase when 1 per cent $\mathrm{NaCl}$ is added to pure water (8).

\section{Creation of Gold Surface-Enrichment on Gold Alloys}

The following steps are criteria for the creation of a gold-enriched surface on a gold alloy (3):

I The alloying elements are preferentially oxidized compared with gold

II The reaction products are dissolved rather than precipitated at the metal-solution interface.

Additions of sodium chloride to pure water should speed up the oxidation of copper (to copper chloride), which is sufficiently soluble for step II above to be fulfilled. On the other hand, additions of sodium sulphide to pure water should also speed up the oxidation

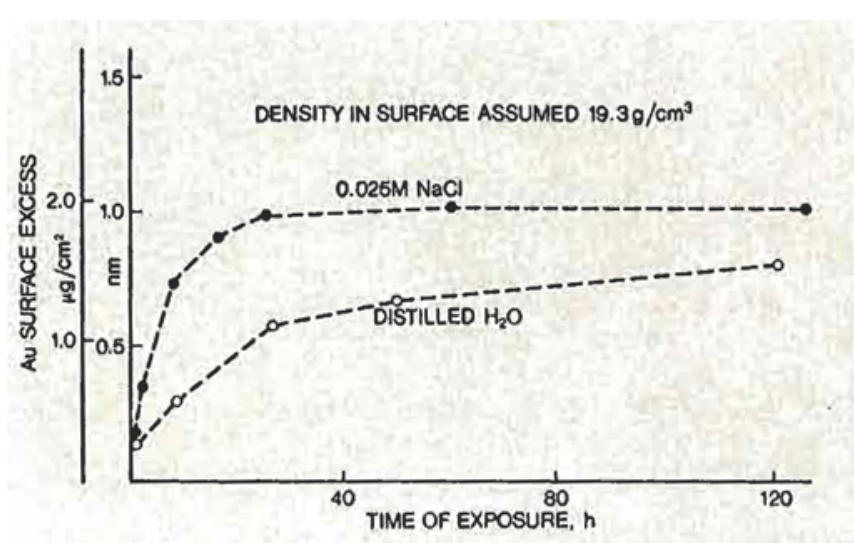

Fig. 4 Gold surface enrichment vs. time of exposure of alloy A1 in the presence and absence of $\sim 1 \%$ chloride addition to water. ESCA examination

of copper (to cuprous or cupric sulphide). However these compounds are insoluble in water - resulting in tarnishing of the alloy by formation of the copper sulphides. In pure water zinc and copper dissolve regardless of being in a gold alloy or as metals (8). In an aqueous solution containing many anions such as $\mathrm{Cl}^{-}, \mathrm{HS}$ and $\mathrm{OH}^{-}$besides oxygen, there are many pathways for oxidation of copper and zinc with the oxidation products having sufficiently high solubility to fulfill step II above. In contrast to the situation with copper and zinc, silver will only oxidize to $\mathrm{Ag}_{2} \mathrm{~S}$ which is insoluble.

An even distribution of gold is created by the single phase structure of the test alloys and this is beneficial to the limitation of the release of unstable alloying elements by surface enoblement. The need for characterization of microstructure in gold alloys in tarnish situations has recently been pointed out by Treacy and German in this journal (9).

Some Consequences of the Constructive (Selective) Dissolution of Copper and Zinc Leading to Passivation of Gold Alloys

The dissolution kinetics of copper, silver and zinc as described in the previous section can offer an explanation of the differences in appearance of the alloys shown in Figure 5. The gold-silver alloy (As in Table I) tarnishes in the sulphide solution while the alloys $A 1$ and $A 4$ do not. The gold-silver and the gold-copper alloy have also been exposed to saliva in the oral cavity of four individuals and, as is well known, saliva contains both sulphides and chlorides. The results are reproduced in Table II and are discussed in detail in (10). A pre-passivation, by means of constructive or selective dissolution, was performed on alloy $A 1$ in chloride solution thus enriching the surface with gold. A subsequent exposure of the sample to a relatively concentrated sulphide solution only slightly changed the 


\section{$p S \approx 450 h$}
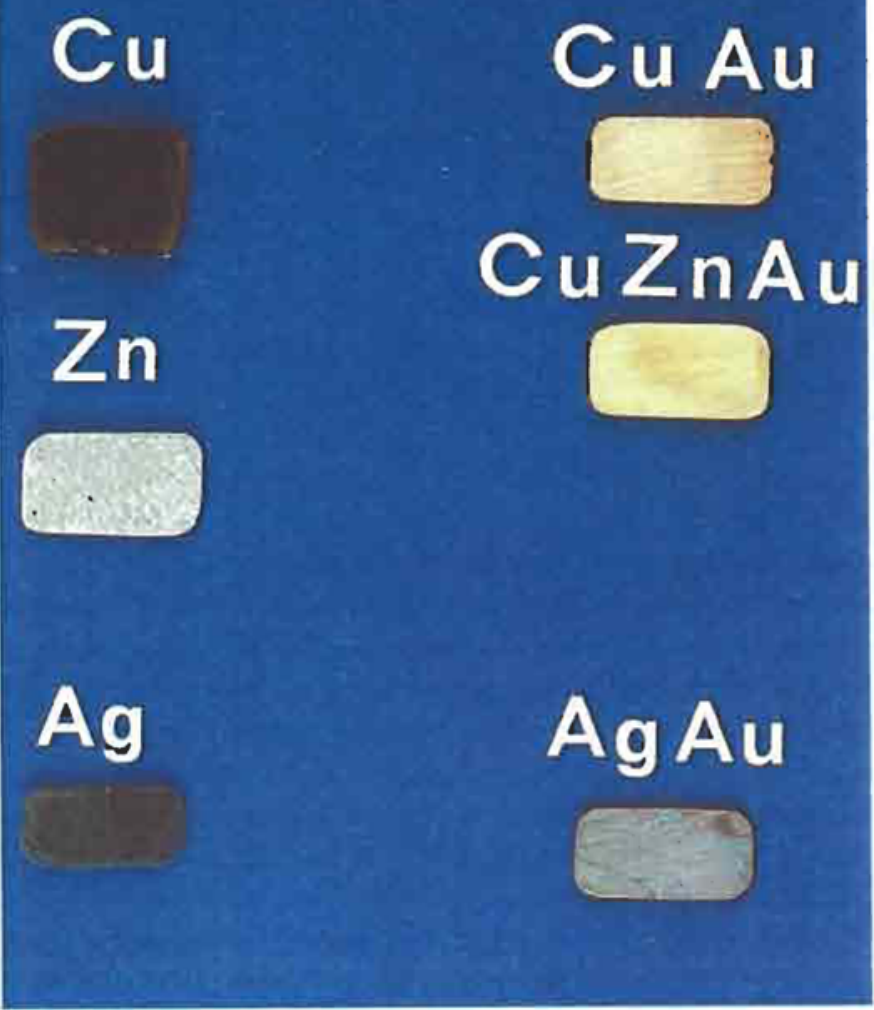

surface composition (Table III). A sample with nominal composition, that is no pre-passivation, became depleted in gold due to the selective oxidation of copper to insoluble copper sulphides (Table III).

A selective oxidation of zinc and copper relative to gold takes place also in air at room temperature (Figure 6). After approximately half a year almost no gold but essentially copper and zinc in oxidized states were detected by ESCA (solid circles in Figure 6). This selective oxidation of zinc and copper is suppressed and delayed when a pre-passivation in $\mathrm{NaCl}$-containing water precedes the exposure to air. In Figure 6 , it is found that the gold surface content of the pre-passivated sample (open circles in Figure 6) returns to the nominal bulk value (28 atomic per cent) in $\sim 3$ months.

It is of principal interest to follow the changes in surface composition in an oxidative free environ ment such as in a vacuum (partial pressure of oxygen $<10^{-5} \mathrm{~N} / \mathrm{m}^{2}$ ). As expected, the sample with nominal surface composition (solid triangle in Figure 6) did

\section{Table II \\ Atomic Per Cent Gold in Alloy \\ Surfaces After Exposure in Oral \\ Cavities of 4 Individuals for 8 Days}

(ESCA)

\begin{tabular}{c|rrrr} 
Test & \multicolumn{4}{|c}{ Individuals } \\
alloy & 1 & 2 & 3 & 4 \\
\hline A4 & 40 & 63 & 62 & 54 \\
A5 & 22 & 23 & 21 & 23
\end{tabular}

\begin{tabular}{|c|c|c|c|}
\hline \multicolumn{4}{|c|}{$\begin{array}{c}\text { Table III } \\
\begin{array}{c}\text { Atomic Per Cent Gold in Surface After Different Exposures } \\
\text { of Alloy A1 (ESCA) }\end{array}\end{array}$} \\
\hline \multirow[t]{2}{*}{ Alloy } & \multicolumn{2}{|c|}{ Exposure Conditions } & \multirow{2}{*}{$\begin{array}{l}\text { Surface Gold, } \\
\text { Atomic } \%\end{array}$} \\
\hline & Time & Ion Concentration ${ }^{\star}$ & \\
\hline A1 & $20 \mathrm{~h}$ & $p S=3.5$ & 19 \\
\hline $\mathrm{A} 1$ & $20 \mathrm{~h}$ & $\mathrm{pCl}=1.6$ & 60 \\
\hline $\mathrm{A} 1$ & $20 \mathrm{~h}$ & $\mathrm{pCl}=1.6$ & \\
\hline & then $20 \mathrm{~h}$ & $p S=3.5$ & 59 \\
\hline
\end{tabular}

*Ion concentrations expressed in $\mathrm{pH}$ form.

Thus $\mathrm{pX}=\mathrm{N}$ means $10^{-\mathrm{N}}$ gram ions/litre

Fig. 5 Copper, silver, zinc and alloys AI, A4 and A5 after 50 hours of immersion in $10^{-4} \mathrm{M}$ sulphide solution

not change significantly during the exposure in vacuum. On the other hand, the initial gold-enriched sample (open triangle in Figure 6) slowly decreased in enrichment. This might well be the result of interdiffusion at room temperature of this alloy. An interdiffusion at a rate of $10^{-21} \mathrm{~cm}^{2} / \mathrm{s}$ can be estimated from Figure 6 , which is an acceptable value (11). This interdiffusion should not be confused with a possible high mobility in gold alloys under strong oxidative conditions which is discussed in $(12,13)$. A high surface (lateral) diffusion could achieve the formation of a thin, dense, gold overlayer especially during the process of selective dissolution in the mild solutions found in practice.

This possible circumstance is supported by a low mobility which is found in Figure 6 (open triangle), and which indicates a gold surface layer containing relatively few vacancies. If the ratedetermining step in the dissolution process is diffusion of copper and zinc to the alloy/solution interface it is possible to estimate such an ultimate dissolution rate to be in the range $10^{-4}-10^{-3} \mu \mathrm{g} / \mathrm{cm}^{2} . \mathrm{h}$ (See also Figure 2). 


\section{Concluding Remarks}

Analyses of gold alloying elements such as copper and zinc found in test solutions (gammaspectrometry), and changes in alloy surface composition (ESCA), after exposure of alloy samples to tarnish solutions are quantitative and in good agreement.

The very initial release rate of copper and zinc from a goldcopper-zinc alloy is the same in magnitude as the release rates from copper and zinc metals. After removal, by constructive selective dissolution, of $\sim 2 \mu \mathrm{g} / \mathrm{cm}^{2}$ copper plus zinc - corresponding to a $\sim 1 \mathrm{~nm}$ thick gold overlayer with the density of metallic gold - the release rate in $0.025 \mathrm{M} \mathrm{NaCl}$ solution is $\sim 1 \mathrm{ng} / \mathrm{cm}^{2}$.h.

Silver-containing low gold alloys ( $\sim 30$ atomic per cent gold) are more sensitive to tarnishing in saliva-like solutions containing sulphide and chloride than low gold alloys with copper or zinc as alloying elements, although both copper and silver sulphides are virtually insoluble. In the saliva-like solutions copper can oxidize to $\mathrm{Cu}_{x} \mathrm{O}_{y}(\mathrm{OH})_{z} \mathrm{Cl}$, with a subsequent chemical dissolution of this type of reaction product. No corresponding pathways of oxidation exist for silver which consequently only oxidizes to insoluble silver sulphide giving rise to tarnish and discolouration of the gold alloy.

The ennoblement (to $\sim 1 \mathrm{~nm}$ ) in the surface of a gold-copperzinc alloy resists some months of exposure to air at room temperature - a time period during which the gold surface composition returns to the nominal bulk value of the alloy. The

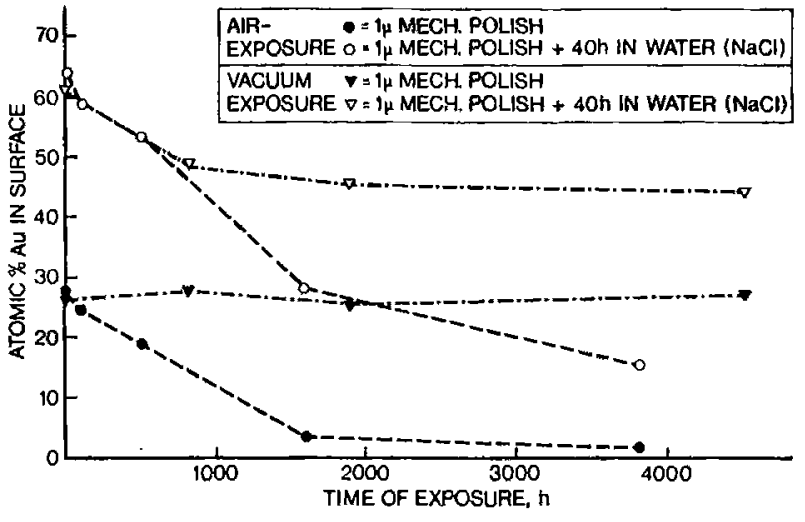

Fig. 6 Gold surface content as measured by ESCA on alloy $A 1$ after exposure in air and vacuum $\left(\mathrm{pO}_{2}<10^{-5} \mathrm{~N} / \mathrm{m}^{2}\right)$ respectively. Nominal $(28 \mathrm{at} . \%)$ and enriched (62 at. \%) gold surface contents were the initial states during the exposures in air and vacuum

main driving force for the diffusion kinetics of this process is oxidation of zinc and copper. Measurement of diffusion at room temperature in a negligible oxidative environment (that is, a vacuum), gives an experimental value of interdiffusion of the order of $10^{-21} \mathrm{~cm}^{2} / \mathrm{s}$ in the surface zone of a gold-copper-zinc alloy.
1 G. Hultquist and C. Leygraf, Mater. Sci. Eng., 1980, 42, 199

2 C. Ingersoll, IADR Program. Abstr. 1975, 54, No. 46

3 G. Hultquist and H. Herd Comos. Sot. 1984, 24, (9), 789-80s

4 D. Brune, B. Forkmann and B. Persson, 'Nuclear Analyric Chemistry' pp. 201, 326. Student Litt, Chartwel!-Bratt Lid., Lund, Sweden 1984

5 D. Brune, G. Hultquist and C. Leygraf, Scand.J. Dent. Res., 1984, No. 3, 262

6 G. Hultquisı. C. Leygraf and D. Brune, J. Electrochem. Soc, 1984, 131, (8) 1773

\section{References}

7 C.C. Chang, Surf. Sci., 1975, 48, 9

8 G. Hulrquist, Article in Dagens Industri, 19th June, 1984 (In Swedish)

9 D.J. Treacy and R.M. German, Gold Bull., 1984, 17, (2), 46

10 H. Hero G. Hulrquist and A. Oden, submitced for publication in Biomater.

II R. Ramstetrer, G. Lampert, A. Seegerand W. Schüle, Pbys. Stat. Sol. 1965, 8. 863

12 H.W. Pickering and C. Wagner, J. Electrochem. Soc, 1967, 114, (7), 698

13 A.J. Forrv, Gold Bull., 1981, 14, (1), 25

\section{Gold Microelectrodes in Molecule-Based Transistors}

Three researchers from MIT Department of Chemistry have reported recently (H. Whitc, G.P. Kittlesen and M.S. Wrighton, J. Am. Chem. Soc., 1984, 106, 5375-5377) on the fabrication of a chemically derivatized nicroelectrode array that can function as a transistor when immersed in an electrolyte solution. The key finding is that it can be shown that a small signal (charge) needed to turn on the device can be amplified. The device described mimics the fundamental characteristics of a solid-state transistor, since the resistance between two contacts can be varied by a signal to be amplified. The chemical transistor consists of a set of three (drain, gate and soutce) gold microelectrodes covered with polypyrrole. Three features are essential: (1) the three independent gold microelectrodes are closely spaced, $1.4 \mu \mathrm{m}$ apart, allowing an easily measurable current to pass between the source and drain when drain voltage $V_{D}$ is significant and gate volsage $V_{B}$ is above a threshold value $\mathrm{V}_{\mathrm{r}} ;$ (2) the polypyrole exhibits a sharp change in conductivity upon oxidation; the potential at which this occurs is $\mathrm{V}_{\mathrm{j}} ;(3)$ each of the microelectrodes can be individually contacted. The input signal to the gate to be amplified is that needed to oxidize the polypyrrole, at which potential the polypyrrole switches from insulacing to conducting. The threshold voltage, and the magnitude of signal needed to achieve it, can be altered by variation of the molecule-based material. The transistor reported by White etal. had no immediate practical application at the time of their publication, however the authors point out that considerable interest exists in interfacing microelectronic devices with chemical and biological systems for sensor applications, and in 'molecular electronics' in general. 